\title{
STUDI EKSPLANATORI DAN KONFIRMATORI TENTANG MODEL PEMBELAJARAN PROBLEM SOLVING BERDASARKAN KEJADIAN 26:1-35 DI KALANGAN MURID SOM GEREJA BETHANY SE-KOTA SURABAYA
}

Renny Tade Bengu

Sekolah Tinggi Teologi Injili Efrata Sidoarjo

rennysomsby@gmail.com

\begin{abstract}
In planning learning in the classroom, teachers can use problem solving learning models so that students have general patterns of learning behavior, train critical thinking to have divergent thinking patterns, are trained to reflect on their perceptions and can achieve the expected competencies or learning goals. This study will examine the implementation of a problem solving learning model based on Genesis 26:1-35 in the Bethany Church in Surabaya. This study used an explanatory survey method and was validated by reviewing the literature as a theoretical basis and distributing questionnaires to a sample of 86 students at the Serving Orientation School (SOM) in Surabaya. As a result, it was found that of the five dimensions contained in Genesis 26:1-35, it was found that the most prominent aspect of implementing the problem solving learning model among SOM Bethany students in Surabaya was 'other learning resources' and the category of educational background being the most dominant. for the implementation of problem solving learning model based on Genesis 26:1-35 in SOM students of Bethany Church Sekota Surabaya.
\end{abstract}

Keywords: Learning Model, Problem Solving, Genesis 26:1-35

\begin{abstract}
Abstrak
Dalam merencanakan pembelajaran di kelas guru dapat menggunakan pembelajaran dengan model problem solving agar peserta didik memiliki pola umum perilaku pembelajaran, melatih untuk berpikir kritis memiliki pola pikir divergen, terlatih merefleksikan persepsinya dan dapat mencapai kompetensi atau tujuan pembelajaran yang diharapkan. Studi ini akan meneliti implementasi model pembelajaran problem solving berdasarkan Kejadian 26:1-35 di Gereja Bethany se-kota Surabaya. Penelitian ini menggunakan metode survey eksplanatori dan divalidasi dengan tinjauan pustaka sebagai landasan teori dan penyebaran kuesioner kepada 86 sampel siswa di Sekolah orientasi Melayani (SOM) di Surabaya. Hasilnya, ditemukan bahwa dari lima dimensi yang termaktud dalam Kejadian 26:1-35 diperoleh bahwa aspek yang paling menonjol dari penerapan model pembelajaran problem solving di kalangan siswa SOM Bethany di Surabaya adalah 'sumber belajar lainnya' dan kategori latar belakang pendidikan menjadi yang paling dominan untuk implementasi model pembelajaran problem solving berdasarkan Kejadian 26:1- 35 di murid SOM Gereja Bethany Sekota Surabaya.
\end{abstract}

Kata Kunci : Model Pembelajaran, Problem Solving, Kejadian 26:1-35 


\section{PENDAHULUAN}

Para ahli pendidikan telah mengembangkan macam-macam metode, strategi pembelajaran untuk memudahkan guru mencapai tujuan pengajaran sehingga dapat lebih efektif dan sistematis dalam mengajar. Guru haruslah menjadi teladan (modelling) dan ikut menyesuaikan metode dengan era sekarang. ${ }^{1}$

Menurut Wina Sanjaya mengatakan bahwa, yang menjadi kekurangan dalam proses pembelajaran yaitu kurangnya upaya guru dalam mengembangkan kemampuan berpikir murid. ${ }^{2}$ Terbukti sampai sekarang masih ada sekolah- sekolah mempraktikkan pembelajaran secara konvensional, yaitu tiba, duduk, catat serta hafal (DDCH). ${ }^{3}$ Hal ini juga terlihat pada pembelajaran yang berlangsung di SOM Bethany Nginden dan SOM Bethany Manyar dan SOM Sekota Surabaya. Dari hasil observasi di Bethany Sekota Surabaya ditemukan bahwa pada saat pembelajaran berlangsung siswa tidak memiliki kesempatan untuk berdiskusi, guru mengajar hanya satu arah, akibatnya beberapa murid menjadi pasif, tidak antusias, sibuk sendiri, susah bertanya dan menyampaikan pendapatnya, ada yang bermain handphone saat pelajaran berlangsung.

Dunia kerja pada abad ke-21 ini, menuntut peserta didik memunyai banyak ketrampilan, salah satunya adalah ketrampilan berpikir. F.Dennis mengemukakan bahwa, "pembelajaran dengan cara menghafal akan menghasilkan kurangnya kemampuan berpikir kritis dan rendahnya kreativitas". ${ }^{4}$ Untuk merangsang kemampuan berpikir kritis, maka guru perlu menggunakan proses pembelajaran yang menuntut aktivitas murid, menggunakan berbagai kecerdasannya, berdiskusi, meneliti isu nyata yang ada, mengamati, memecahkan masalah yang disajikan oleh guru. ${ }^{5}$ Di SOM Bethany Surabaya terlihat bahwa peran guru dalam pembelajaran masih sangat penting bagi siswa yang belum terbiasa belajar mandiri. Beberapa siswa cepat bosan saat belajar. Berdasarkan hasil wawancara yang dilakukan peneliti, sebagian besar guru di SOM Bethany Surabaya hanya menggunakan bahan ajar berupa buku ajar dari departemen SOM Bethany Surabaya. Model pembelajaran problem solving memiliki tujuan pembelajaran yaitu melatih murid berpikir tingkat tinggi sehingga guru dapat membimbing murid dapat mengintervensikan ide baru berupa konsep dan prinsip. ${ }^{6}$ Dengan penerapan model problem solving peserta didik memiliki pola pikir yang divergen, melatih kebiasaan berpikir kritis sehingga murid dapat menemukan berbagai cara penyelesaian. ${ }^{7}$ Dari pengertian di atas, peneliti menyimpulkan bahwa dalam merencanakan pembelajaran di kelas guru dapat menggunakan pembelajaran dengan model problem solving agar peserta didik memiliki pola umum perilaku pembelajaran, melatih untuk berpikir kritis memiliki pola pikir yang berbeda, terlatih merefleksikan persepsinya dan dapat mencapai kompetensi atau tujuan pembelajaran yang diharapkan.

\footnotetext{
${ }^{1}$ Suwana, Pengajaran Mikro, 1st ed. (Yogyakarta: Tiara Wacana, 2005). 34

${ }^{2}$ Wina Sanjaya, Strategi Pembelajaran Berorientasi Standar Proses Pendidikan, 1st ed. (Jakarta: Kencana, 2008). 13

${ }^{3}$ Winastwan Gora dan Sunarto, Pakematik: Strategi Pembelajaran Inovatif Berbasis TIK, 1st ed. (Jakarta: Elex Media Komputindo, 2010). 2

${ }^{4}$ Slameto, Belajar Faktor-Faktor Yang Mempengaruhinya, 1st ed. (Jakarta: Rineka Cipta, 2013). 17

${ }^{5}$ Rusman, Model-Model Pembelajaran, 5th ed. (Jakarta: PT. Rajagrafindo Persada, 2012). 234

${ }^{6}$ Rusman, Model-Model Pembelajaran, 5th ed. (Jakarta: PT. Rajagrafindo Persada, 2012). 243-245

${ }^{7}$ Pangesti Wiedarti, Menuju Budaya Menulis: Suatu Bunga Rampai, 1st ed. (Yogyakarta: Tiara Wacana, 2005). 96
} 
Problem solving sebagai model pembelajaran berdasarkan Kejadian 26:1-35 yaitu suatu pola pembelajaran dengan menggunakan langkah-langkah yang akan mengarahkan murid melakukan analisa, mendiskusikan penemuan, menyimpulkan dan mengevaluasi sehingga akan mencapai tujuan murid terlibat aktif dalam pembelajaran dan berpikir kritis.

Penelitian ini bertujuan untuk menjawab tiga pertanyaan berikut: (1) kecenderungan implementasi model pembelajaran problem solving berdasarkan Kejadian 26:1- 35 di kalangan murid SOM Gereja Bethany Se-kota Surabaya? (2) Dimensi apa yang dominan dalam implementasi model pembelajaran problem solving berdasarkan Kejadian 26:1- 35 di kalangan murid SOM Gereja Bethany Se-kota Surabaya? (3) Manakah yang dominan dari latar belakang implementasi model pembelajaran problem solving berdasarkan Kejadian 26:1- 35 di kalangan murid SOM Gereja Bethany Se-kota Surabaya?

Hipotesa yang peneliti ajukan yaitu: Pertama, Kecenderungan implementasi model pembelajaran problem solving berdasarkan Kejadian 26:1-35 di kalangan murid SOM Gereja Bethany se-kota Surabaya adalah sedang. Kedua, Ada lima dimensi model pembelajaran problem solving berdasarkan Kejadian 26:1-35, maka dimensi "Sumber belajar lain" lebih dominan menentukan implementasi model pembelajaran problem solving berdasarkan Kejadian 26:1-35 di kalangan murid SOM Gereja Bethany se-kota Surabaya. Ketiga, latar belakang "Pendidikan" merupakan faktor yang dominan menentukan penerapan model pembelajaran problem solving berdasarkan Kejadian 26:1-35 di kalangan murid SOM Gereja Bethany se-kota Surabaya.

\section{METODOLOGI}

Metode penelitian ini adalah survey yang bersifat eksplanatori- konfirmatori. Sasmoko dkk mengatakan bahwa, dalam penelitian ini terdapat penelitian kualitatif (penelitian eksploratif) dan penelitian kuantitatif (penelitian eksplanatori) yang harus menjelaskan penelitian dan mengkonfirmasi penelitian (penelitian validasi). ${ }^{8}$ Metode survei untuk penelitian secara kuantitatif bersifat konfirmatori. Cara yang dilakukan yaitu dengan menggunakan sampel yang representative untuk mengambil kesimpulan berdasarkan pengumpulan data dari populasi langsung. ${ }^{9}$ Sedangkan penelitian ini dikatakan explanatory karena mengkaji lebih jauh variabel dependen (Y) melalui pengembangan variabel eksogen dan endogen. Hasil studi eksplanatori atau studi mendalam terhadap variabel-variabel yang terkait dengan model pembelajaran problem solving berdasarkan Kejadian 26:1-35 di kalangan murid SOM Gereja Bethany se-kota Surabaya. Dan disebut konfirmatori karena penelitian ini juga mengkaji secara mendalam melalui

indikator sebagai variable moderat yang tugasnya untuk memperdalam temuan dari analisis responden.

\footnotetext{
${ }^{8}$ Frederikus Fios and Sasmoko, Neuro Research Method: A Synthesis Between Hermeneutics and Positivism, Advanced S. (American Scientific Publishers, 2016). 2204

${ }^{9}$ Fred N Kerlinger and Howard B Lee, Foundation of Behavioral Research (Forth Worth: Harcount College Publisher, 2000).
} 


\section{HASIL DAN PEMBAHASAN}

Hasil pembasan karya ilmiah ini diuraikan sebagai berikut:

Problem Solving dengan "Mendengarkan" (Kej. 26:2-4)

Ketika terjadi masalah kelaparan yang sangat hebat, Tuhan melakukan dua hal kepada Ishak, yaitu menampakkan diri dan berfirman. Kata menampakkan diri memakai kata Ibrani ראה (ra'ah) dan kata berfirman memakai kata Ibrani אמר ('amar). "mendengarkan" (har. "mendengar untuk melakukan"). Qal imperfect, "memelihara," Qal imperfect memberikan pengertian yaitu tindakan sedang berjalan.

Mendengar adalah memberikan perhatian kepada apa yang sedang disampaikan oleh orang lain. Seorang murid perlu mendengar dan memperhatikan dengan seksama ketika guru sedang mengajar. Dalam hal ini hal mendengar firman Tuhan, murid dituntut untuk fokus dan lebih memperhatikan sehingga apa yang di dengar bukan hanya sekedar didengar akan tetapi didengar serta mampu mengaplikasikan dalam diri. Mendengar secara harafiah menurut kata Ibrani אמר ('amar) adalah "menyebutkan peristiwa dibelakang atau dibalik" yang mempunyai makna menjelaskan sesuatu sungguh-sungguh, memasang telinga dengan penuh perhatian untuk mendengar , memperhatikan, mengindahkan. ${ }^{10}$ Dalam psikologi Ibrani ucapan seseorang dipandang sebagai keberadaan yang nyata dari si pembicara sendiri. Kata ('amar) yang diterjemahkan firman atau perkataan, selaku ucapan Allah adalah penyataan diri Allah sendiri. Kata- kata אמר ('amar) dalam PL dipakai 394 kali tentang bagaimana Allah berkomunikasi kepada manusia. ${ }^{11}$

Perhatikanlah, mendengar kembali apa yang diterima dan menelaahnya sampai benar-benar mengerti. Kamu telah mendengarnya, tetapi kamu tidak mengerti. Mendengar saja tidak cukup, bila tanpa pengertian (Neh. 8:2). Dengan pertolongan dari Allah-lah yang dapat memberikan kepada seseorang pengertian untuk dapat memahami dengan akal budinya. Dalam hal mendengar penerima pesan dapat memahami pesan apa yang telah diterima, dan menanggapi adalah kemampuannya dalam memberikan respon. Wujudnya dapat bermacam bentuk antara lain mengangguk-angguk, mengerjakan seperti apa yang sudah didengarnya. ${ }^{12}$

Dalam Kejadian pasal 1 dikatakan bahwa Tuhan menciptakan langit dan bumi dengan berfirman. Dalam kehidupan manusia, Firman Tuhan harus didengar dan dilakukan (Mzm. 103:20); tidak dapat ditambah atau dikurangi (Ul. 12:32). Firman Tuhan untuk selama-lamanya (Yes. 40:8), tidak akan kembali sampai digenapi (Yes. 55:11). Firman Tuhan, wahyu Tuhan, juga diberikan kepada para nabi.

Tuhan membentuk, memperlengkapi, serta mempersiapkan anak-anak-Nya menjadi murid. Untuk menjadi murid, maka haruslah menaruh perhatian yang sungguhsungguh terhadap ajaran Sang Guru. Dengan mendengar akan memberikan ketajaman pendengaran seorang murid. Maka hasil dari mendengar inilah yang akan menghasilkan seseorang mendapatkan tuntunan, nasihat yang akan menghasilkan dapat mengambil suatu keputusan dengan tepat.

Jadi, model pembelajaran problem solving" mendengarkan adalah " guru menyajikan masalah kepada peserta didik dimana guru memberikan instruksi agar murid mendengarkan dengan memperhatikan sungguh-sungguh, fokus, menaruh perhatian terhadap arahan dan petunjuk guru.

\footnotetext{
${ }^{10}$ Robert Smith, Studies in Genesis, 1st ed. (Oak Harbor: Derdick Publishing, 1997). 251

${ }^{11}$ Jack Hayford, Examining Excellence in The Creator's Ways: A Study in The Book of Genesis, $1 \mathrm{st}$ ed. (Nashville: Thomas Nelson, 1997). 112

${ }^{12}$ A Anditha Sari, Komunikasi Antar Pribadi, 1st ed. (Yogyakarta: Deepublish, 2017). 8-9
} 


\section{Problem Solving dengan "Berusaha" (Kej. 26:12)}

Ketika terjadi bencana kelaparan, dan Ishak tinggal di negeri asing, maka ia melakukan sebuah aktivitas yang membuatnya diberkati Tuhan, yaitu menabur. Kata ibrani זרע (zara') secara harafiah memiliki arti mengolah bibit atau benih, mengandung, menabur, atau aktivitas yang berkaitan dengan mengolah lahan pertanian. ${ }^{13}$ Pada zaman Perjanjian Lama, menabur benih adalah pekerjaan yang sederhana. Meskipun ayat ini tidak menjelaskan metode bertani secara rinci, ayat ini berasal dari Perjanjian Lama (Yes. 28: 24-25; Yer. 4:3; dan Hos. 10:11-12) dan dari sumber-sumber rabinik, ayat ini memberikan pelajaran yang berlangsung sepanjang musim panas . Untuk waktu yang lama, iklim sangat panas, sehingga petani harus mencangkul, menabur dan menutup sampai musim hujan tiba dan benih akan tumbuh. ${ }^{14}$

Menabur benih berkaitan bercocok tanam. Pekerjaan pertama manusia waktu Adam dan Hawa di taman Eden dapat dikatakan adalah bercocok tanam seperti dalam Kejadian 2:15, "taman harus diusahakan dan dipelihara". Anak Adam yakni Kain pekerjaannya sebagai petani sedangkan anak lainnya yakni Habel bekerja sebagai peternak kambing domba (Kej. 4:2). Dan keturunan Adam selanjutnya yakni Nuh merupakan orang yang pertama mengusahakan kebun anggur (Kej. 9:20). ${ }^{15}$ Para bapa leluhur Israel bekerja sebagai peternak kambing domba yang mahir.

Mark Water mengungkapkan ada dua hal penting dalam narasi tentang Ishak yang diberkati karena menabur, yaitu: ${ }^{16}$ (1) Dapat dipetik pelajaran bahwa Tuhan memberkati orang yang mau berusaha atau bekerja. Sebelumnya, Tuhan sudah berfirman kepada Ishak dan Ishak sudah mendengarkan firman Tuhan. Maka, Firman Tuhan yang didengar perlu dibarengi dengan usaha atau tindakan. Hal inilah yang ditangkap oleh Ishak. Ia percaya kepada janji Tuhan, sehingga ia yakin bahwa usahanya (menabur benih) akan diberkati Tuhan; (2) Dapat dipetik pelajaran bahwa kerelaan hati sangat penting dalam narasi tentang Ishak ini. Kondisi kelaparan yang dialami sebelumnya tentu secara logika membuat modal Ishak untuk menabur menjadi terbatas, dan tentunya segala yang ia miliki saat kesusahan ini tentu sangat berharga. Jika sesuatu yang ada di tangan seorang percaya itu tidak cukup untuk memenuhi kebutuhan, maka jadikanlah itu sebagai benih untuk ditaburkan, dari sanalah Tuhan memberikan solusinya. Kisah janda di Sarfat yang dipelihara Tuhan di masa kelaparan, juga memberikan pelajaran bahwa setiap orang yang menabur dalam kekurangannya maka ia menuai dengan kelimpahan. Janda di Sarfat, ia menabur dari kekurangannya sesuai dengan perintah Tuhan untuk memberi makan Nabi Elia (1Raj. 17:7).

Dalam Taurat, Musa menyampaikan kepada tua-tua Israel untuk mengembangkan pertanian (Ul. 26:1-11). Bangsa Israel bekerja dengan bercocok tanam di tanah Kanaan ini merupakan pekerjaan yang terhormat sebab mendapatkan hasil karena bekerja. Dan hukum Taurat mengatur bahwa setiap tanah yang sudah diberikan tidak diperbolehkan untuk menjualnya atau melepaskan haknya melainkan tetap menjadi milik pusaka kaum keturunannya (Ul. 19:14).

Dampak dari aktivitas Ishak yang menabur dijelaskan oleh kalimat שער (sha'ar) מאה (me'ah) or מאיה (me'yah) יהוה (Yarak) ברך (Yehovah) yang berarti Ia (Ishak) diberkati Tuhan. Berkat adalah suatu pemberian dari Tuhan yang menghendaki agar

\footnotetext{
${ }^{13}$ Stuart Briscoe, The Preacher's Commentary Series: Volume I, 1st ed. (Nashville, Tennessee: Thomas Nelson, 1987). 182

${ }^{14}$ H.N Ridderbos, Studies in Scripture and Its Authority, 1st ed. (St. Catharines: Paideia Press, 1978). 50

${ }^{15}$ Ibid.

${ }^{16}$ Mark Water, The Book of Genesis Made Easy, 1st ed. (Hampshire: John Hunt Publishers Ltd, 2000). 31
} 
umat-Nya memiliki suatu hidup yang berkelimpahan yang tidak saja bersifat materi saja namun didalamnya termasuk hidup yang menjadi berkat serta memuliakan Tuhan. ${ }^{17}$ Oleh karena itu haruslah sebagai umat memiliki hubungan komunikasi dengan Tuhan serta memuliakan Tuhan. Memuliakan Tuhan lewat hati yang bersyukur serta pujian yang keluar dari hati kepada Allah.

Jadi, kesimpulan problem solving "menabur" adalah tindakan yang dilakukan guru pada siswa untuk memahami masalah nyata, menentukan apa yang mereka ketahui, apa yang perlu mereka ketahui dan bagaimana atau tindakan apa yang harus dilakukan untuk memecahkan suatu masalah.

\section{Problem Solving dengan "Media Pembelajaran" (Kej. 26:18)}

Ketika Ishak makin diberkati Tuhan, terjadilah sebuah masalah yaitu timbul kecemburuan diantara orang Filistin dan akhirnya Abimelekh, raja Gerar mengusir Ishak. Dalam persoalan ini, yang Ishak lakukan adalah pergi menetap di lembah Gerar חפר (chaphar) ארב (mayim (o’er) yang menunjukkan aktivitas menggali tanah untuk mencari sumber air. ${ }^{18}$ Curah hujan di Palestina sangat sedikit, sehingga sumur menjadi sangat penting. Sumur menjadi aset berharga disebabkan mendapatkan air yang sulit karena musim kering yang cukup lama, apalagi di daerah padang gurun. sehingga menuntut bekerja keras untuk menggalinya. Sehingga kebanyakan untuk kepemilikan sumur dapat menimbulkan perbantahan serta pertikaian. Pada zaman lampau, memanfaatkan sumur tanpa izin dianggap sebagai pelanggaran terhadap hak milik (Bil. $20: 17,19 ; 21: 22){ }^{19}$

Karena hal tersebut pada zaman Abraham, yang mendapatkan sumur maka ditetapkan kepemilikannya seperti Abraham yang menggali sumur tersebut maka Abraham berhak atas kepemilikan sumur di Bersyeba (Kej. 21:25-31; 26:20, 21). Tetapi dalam Kejadian 26:1-18 menyatakan bahwa setelah kematian Abraham oleh bangsa Filistin mengabaikan kepemilikan sumur milik Abraham kepada ahli waris yakni Ishak, bahkan mereka menutup sumur yang digali oleh hamba-hamba Abraham.

Keputusan Ishak untuk menggali sumur adalah sebuah keputusan yang menunjukkan iman percayanya kepada Allah. Walaupun menghadapi banyak hambatan, kegagalan, tetapi Ishak memilih tetap tinggal di negeri itu. Ishak tidak pergi ke Mesir yang mungkin bisa saja berlimpah makanannya. Sebab Ishak mendengar firman Tuhan yang datang kepadanya (Kej. 26:2-4) yang menyatakan untuk Ishak tetap tinggal di Gerar. Sehingga walaupun Ishak sudah tidak disukai oleh orang Filistin dan Abimelekh, Ishak tetap taat pada perintah Tuhan untuk tetap tinggal di negeri itu, dan ia bertahan hidup dengan menggali sumur.

Dengan demikian dapat disimpulkan, dalam model pembelajaran problem solving "media pembelajaran" adalah guru membimbing peserta didik untuk melalui media pembelajaran untuk dapat mengumpulkan data-data, informasi, menggali informasi, pengetahuan, konsep, teori untuk menemukan penyelesaian masalah. Melalui problem solving "media pembelajaran" murid belajar mengembangkan kemampuan berpikir, ketrampilan berkomunikasi, dan aktif.

\footnotetext{
${ }^{17}$ Roy Gingrich, The Book of Genesis, 1st ed. (Memphis: Riverside Printing, 1998). 141

${ }^{18}$ Walter Brueggemann, Genesis: A Bible Commentary for Teaching and Preaching, 1st ed. (Atlanta: John Knox Press, 1982). 197

${ }^{19}$ Roy Gingrich, The Book of Genesis, 1st ed. (Memphis: Riverside Printing, 1998). 157
} 


\section{Problem Solving dengan "Sumber Belajar yang Lain"(Kej. 26:19-22)}

Setelah di ayat sebelumnya Ishak menemukan sumur yang berbual-bual airnya, maka terjadi pertengkaran antara gembala Ishak dengan gembala Gerar memperebutkan sumur tersebut. Yang dilakukan Ishak dalam masalah ini adalah ia mencoba mengalah חפר (chaphar) אחר ('acher) yang diterjemahkan 'menggali sumur lain' muncul dua kali pada ayat 21 dan 22.

Terkait dengan usaha Ishak untuk mencari sumur lain ditengah pertikaiannya dengan orang-orang lain, perlu dibangun beberapa penjelasan, yakni: (1) Ishak adalah sosok yang pantang menyerah atau tidak putus asa. Meskipun diusir oleh Abimelekh, dan dua kali bertikai gara-gara permasalahan sumur, namun Ishak tetap berupaya menggali sumur yang lain. Inilah ciri-ciri orang beriman kepada Tuhan, yakni pantang menyerah dan tidak putus asa, sebab yakin bahwa Tuhan yang memberikan janji penyertaan, pasti akan memberkati. ${ }^{20}$; (2) Ishak adalah sosok yang giat bekerja. Meskipun banyak orang yang berusaha menekan dan tidak suka terhadapnya, ia tetap bekerja dengan menggali sumur lain. Keberhasilan di dalam Tuhan merupakan suatu usaha yang didapatkan dengan pemahaman disertai perbuatan atau sikap bekerja yang terencana, fokus, efisien dan berkesinambungan. Allah sanggup menolong bahkan mencukupi kebutuhannya, tetapi bukan berarti Allah memberikan berkat itu turun dari surga secara langsung. Allah juga memakai apa saja, siapa saja untuk sebagai alat mujizat-Nya. Kenneth E Hagin menyatakan bahwa, " ada hal tentang iman untuk masalah keuangan yaitu seseorang tidak bisa menuai jika ia tidak menabur benih." (3) Ishak menggali sumur yang lain dengan harapan sumur tersebut bisa menjadi sarana pemenuhan kebutuhan untuk orang lain (keluarganya, pegawainya, gembalagembalanya, dan hewan hewan ternaknya). Menurut Abraham Alex Tanuseputera, "Berkat yang Tuhan berikan kepada seseorang memiliki maksud bahwa orang tersebut haruslah menjadi berkat buat orang lain yang berkekurangan." 22 Ada misi Allah memberkati umat-Nya. Allah dalam melakukan sesuatu pasti ada maksud dan tujuan. Di wilayah kering dan musim kemarau yang panjang, air adalah hal yang sangat penting. Ishak mengalami musim kemarau sehingga di wilayah Gerar muncul kelaparan. Untuk mendapatkan air yang dilakukan adalah "menggali sumur", Ishak tidak pergi meninggalkan Gerar namun Ishak sabar menanti pertolongan YHWH. Dalam konteks ini sumur yang berhasil di dapatkan menggambarkan kehadiran dan berkat YHWH. Ishak akhirnya menemukan pemecahan masalah yang paling tepat di antara berbagai alternatif, usaha dengan tidak putus asa dan selalu bersandar kepada Tuhan.

Jadi dapat disimpulkan bahwa ketika mengalami masalah demi masalah bukan semakin menyerah melainkan semakin giat berusaha. Dan melalui model pembelajaran problem solving "sumber belajar yang lain", guru membimbing siswa untuk mengidentifikasi pendekatan pemecahan masalah yang paling tepat dari berbagai alternatif pemecahan masalah yang ditemukan siswa. Siswa membuat laporan hasil dari masalah tersebut.

\footnotetext{
${ }^{20}$ Hariono Sumarsono, Hidup Berkelimpahan, 1st ed. (Bandung: Kalam Hidup, 2004). 35

${ }^{21}$ Kenneth E Hagin, Rahasia Hidup Berkelimpahan, 1st ed. (Jakarta: Metanoia, 1996). 46

${ }^{22}$ Abraham Alex Tanuseputra, Kesembuhan Ilahi Dan Berkat, 1st ed. (Surabaya: House of Blessing, 2009). 2
} 


\section{Problem Solving dengan "Refleksi” (Kej. 26:25)}

Mendirikan mezbah memakai kata kerja Ibrani מזבה (banah) מזה (mizbeach) (banah mizbeh). Pada dasarnya מזבח (mizbeach) adalah berada di suatu tempat yang cukup tinggi mempersembahkan korban atau membakar dupa untuk menyembah Allah. ${ }^{23}$ Kata Ibrani מזבח (mizbeach) berasal dari akar kata kerja זבח (zabach) yang artinya membantai, menyembelih, atau mempersembahkan korban, sehingga pada dasarnya yang berarti menyembelih, atau mengorbankan, sehingga pada dasarnya mengacu pada tempat penyembelihan atau pengorbanan. ${ }^{24}$ Kata Ibrani (mizbeach) untuk pertama kali disebutkan setelah air bah, Nuh membangun sebuah mezbah bagi Tuhan dan mempersembahkan korban bakaran di atasnya. (Kej. 8:20). Persembahan zaman Kain dan Habel ini terjadi sebelum peristiwa air bah, penggunaan mezbah sebagai tempat persembahan tidak dinyatakan.

Kebiasaan pada waktu itu mezbah dipergunakan untuk mempersembahkan korban. Juga mezbah sebagai tanda peringatan, yaitu hubungan Allah dengan umat-Nya untuk mengingatkan Kembali pengalaman perjumpaan dengan Allah yang maha kuasa. Bagi bangsa Israel mezbah yang digunakan sebagai tempat korban persembahan dipercayai sebagai sumber kekuatan dan gambaran persatuan (2 Taw. 3:12). Sedangkan bagi bangsa kafir, mezbah dipercayai sebagai tempat makan para dewa. Bentuk mezbah bagi bangsa di sekitar dengan Israel adalah mezbah tidak bertingkat dan bertanduk pada empat sudutnya (secara arkeologis sudah terbukti berkali-kali) (1 Raj. 1:50-51; 2:2829). Memegangi tanduk itu berarti mendapat perlindungan Allah. ${ }^{25}$ Bentuk -bentuk mezbah dalam Perjanjian lama bentuknya berlainan jarang ada yang bentuknya seperti meja (bdk. Yes. 65:11). Dalam kitab Keluaran 20:24-25, Mezbah bagi bangsa Israel menggunakan sebuah gundukan tanah atau sebuah tumpukan batu-batu, yang mana batu-batu itu tidak dinajiskan dengan kerajinan tangan. Mezbah dengan penggunaan batu alam besar atau batu kurban sedikti sekali ditemui di Israel (Hak. 6:20; 13:19; 1 Sam. 6:14; 14:33).

Stuart Briscoe memberikan komentar tentang narasi Ishak yang mendirikan mezbah bagi Tuhan sebagai berikut: ${ }^{26}$ (1) Mezbah yang didirikan oleh Ishak dalam narasi ini adalah sebuah tempat yang Ishak gunakan untuk berkomunikasi dengan Tuhan. Mezbah adalah sarana bagi Ishak untuk memuji dan menyembah Tuhan serta memberikan yang terbaik untuk Tuhan; (2) Mezbah yang didirikan oleh Ishak juga berbicara tentang persekutuannya dengan Allah, sebab melalui mezbah tersebut, ia mempersembahkan sesuatu kepada Allah. Tuhan Yesus berkata bahwa, "Manusia hidup bukan dari roti saja, tetapi dari setiap firman yang keluar dari mulut Allah". Ini berarti manusia dalam persekutuannya dengan Tuhan akan mendapatkan kekuatan dan firman Tuhan memberikan kehidupan bagi manusia (Mat. 4:4); (3) Mezbah yang didirikan oleh Ishak juga menandakan bahwa ia memberikan waktunya untuk Tuhan. Dalam narasi tesebut, Ishak adalah orang yang mengalami berkat Tuhan dengan sangat limpah, sehingga secara logika bisa saja ia sangat sibuk. Di tengah kesibukannya, Ishak

\footnotetext{
${ }^{23}$ George W Coats, Genesis: With An Introduction To Narrative Literature, 1st ed. (Grand Rapids, Michigan: William B, Eerdmans Publishing Company, 1983). 192

${ }^{24}$ Cecil Sherman, Cecil Sherman Formations Commentary Vol. I, 1st ed. (Macon: Smyth \& Helwys Publishing, 2006). 76

${ }^{25}$ George W Coats, Genesis With An Introduction To Narrative Literature, 1st ed. (Grand Rapids, Michigan: William B, Eerdmans Publishing Company, 1983). 195

${ }^{26}$ Stuart Briscoe, The Preacher's Commentary Series Volume I, 1st ed. (Nashville, Tennessee: Thomas Nelson, 1987). 212
} 
memberikan waktunya untuk membuat mezbah dan menyembah Tuhan; (4) Mezbah yang merupakan sebuah kehormatan bahwa suatu pernyataan diri hidup bergantung kepada Tuhan dan mendapatkan berkat dari Tuhan. Mezbah yang diririkan Ishak juga menandakan hidup yang bergantung kepada Allah dan pengucapan syukur atas pemeliharaan Allah.

Dengan demikian disimpulkan bahwa, ketika Ishak mendirikan mezbah yaitu tempat yang digunakan untuk berkomunikasi dengan Tuhan, untuk persekutuannya dengan Allah dan sebagai komunikasi yang aktif dengan "Sang Guru", memiliki hubungan persekutuan, ungkapan syukur atas pertolongan Tuhan pada saat Ishak mengalami persolaan dalam hidupnya "kelaparan di negerinya" dan Allah tidak meninggalkan Ishak namun Ishak mendengar kepada Tuhan, menurutinya dan bergantung kepada Tuhan.

Dalam problem solving "refleksi" adalah guru membantu siswa merefleksikan atau mengevaluasi pemecahan masalah yang dilakukan.

\section{Hasil Penelitian}

Untuk sarana mengambilan dalam penelitian kuantitaif, peneliti menggunakan angket. Kemudian angket tersebut diolah dengan program SPSS 19. Di bawah ini hasil dari pengolahan data SPSS 19.

\begin{tabular}{|c|c|c|c|c|c|}
\hline Variable & Dimensi & No.Soal & r hitung & $r$ tabel & Validitas \\
\hline & \multirow{10}{*}{$\mathrm{X} 1$} & 1 & 0,852 & 0.361 & Valid \\
\hline & & 2 & 0,628 & 0.361 & Valid \\
\hline & & 3 & 0,799 & 0.361 & Valid \\
\hline & & 4 & 0,709 & 0.361 & Valid \\
\hline & & 5 & 0,599 & 0.361 & Valid \\
\hline & & 6 & 0,766 & 0.361 & Valid \\
\hline & & 7 & 0,814 & 0.361 & Valid \\
\hline & & 8 & 0,840 & 0.361 & Valid \\
\hline & & 9 & 0,815 & 0.361 & Valid \\
\hline & & 10 & 0,611 & 0.361 & Valid \\
\hline & \multirow{10}{*}{$\mathrm{X} 2$} & 11 & 0,776 & 0.361 & Valid \\
\hline & & 12 & 0,812 & 0.361 & Valid \\
\hline & & 13 & 0,734 & 0.361 & Valid \\
\hline & & 14 & 0,594 & 0.361 & Valid \\
\hline & & 15 & 0,803 & 0.361 & Valid \\
\hline & & 16 & 0,797 & 0.361 & Valid \\
\hline & & 17 & 0,804 & 0.361 & Valid \\
\hline & & 18 & 0,673 & 0.361 & Valid \\
\hline & & 19 & 0,664 & 0.361 & Valid \\
\hline & & 20 & 0,852 & 0.361 & Valid \\
\hline & \multirow{5}{*}{$\mathrm{X} 3$} & 21 & 0,515 & 0.361 & Valid \\
\hline & & 22 & 0,605 & 0.361 & Valid \\
\hline & & 23 & 0,727 & 0.361 & Valid \\
\hline & & 24 & 0,651 & 0.361 & Valid \\
\hline & & 25 & 0,667 & 0.361 & Valid \\
\hline
\end{tabular}




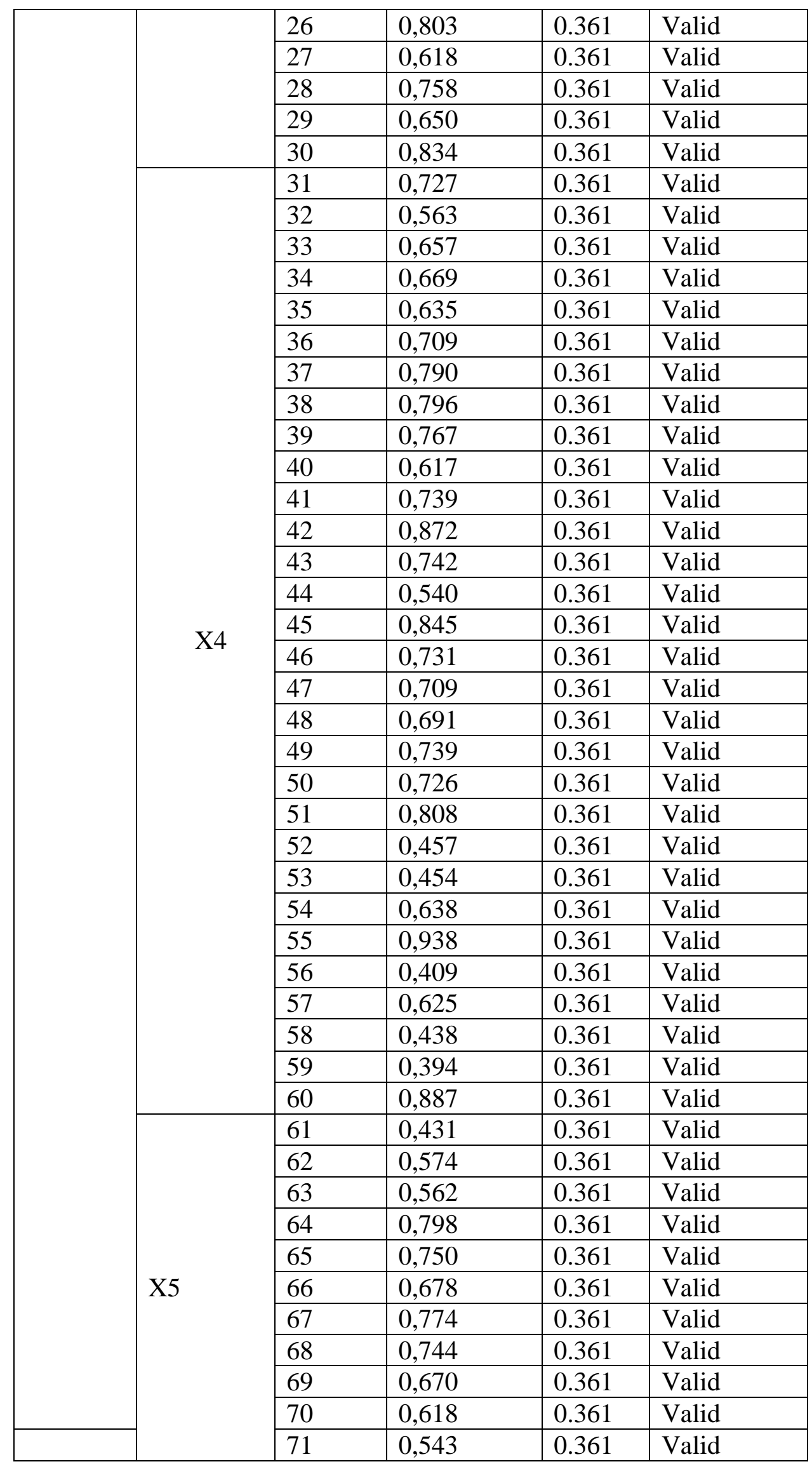




\begin{tabular}{|l|l|l|l|l|}
\hline & 72 & 0,605 & 0.361 & Valid \\
\cline { 3 - 6 } & 73 & 0,647 & 0.361 & Valid \\
\cline { 3 - 6 } & 74 & 0,519 & 0.361 & Valid \\
\cline { 3 - 6 } & 75 & 0,694 & 0.361 & Valid \\
\cline { 3 - 6 } & 76 & 0,547 & 0.361 & Valid \\
\cline { 2 - 6 } & 77 & 0,782 & 0.361 & Valid \\
\cline { 2 - 6 } & 78 & 0,635 & 0.361 & Valid \\
\cline { 2 - 5 } & 79 & 0,757 & 0.361 & Valid \\
\cline { 2 - 5 } & 80 & 0,801 & 0.361 & Valid \\
\cline { 2 - 5 } & 81 & 0,612 & 0.361 & Valid \\
\hline
\end{tabular}

\section{Uji Hipotesa Pertama}

Hipotesis pertama yang diajukan adalah kecenderungan implementasi model pembelajaran problem solving berdasarkan Kejadian 26:1-35 di kalangan murid SOM Gereja Bethany se-kota Surabaya dalam kategori sedang.

Secara analisis data dilakukan dengan Confidence Interval pada taraf signifikan 0,05 .

Selanjutnya akan dilakukan perhitungan dengan melihat angka minimum dan maksimum, kemudian mencocokkan Lower Bound dan Upper Bound antara antara 339.43 sampai dengan 354.40 pada kategori yang ada.

Studi Eksplanatori - Konfirmatori Model Pembelajaran Problem Solving Berdasarkan Kejadian 26:1-35 Di Antara Murid Sekolah Orientasi Melayani Bethany Surabaya (Y) Descriptives

\begin{tabular}{|c|c|c|c|}
\hline & & Statistic & $\begin{array}{l}\text { Std. } \\
\text { Error }\end{array}$ \\
\hline \multirow{14}{*}{$\begin{array}{l}\text { Studi Eksplanatori - } \\
\text { Konfirmatori Model } \\
\text { Pembelajaran Problem } \\
\text { Solving Berdasarkan } \\
\text { Kejadian 26:1-35 Di } \\
\text { Antara Murid Sekolah } \\
\text { Orientasi Melayani } \\
\text { Bethany Surabaya (Y) }\end{array}$} & Mean & 346.91 & 3.735 \\
\hline & Confidence Lower & 33943 & \\
\hline & Interval for Mean $\quad$ Bound & 339.43 & \\
\hline & $\begin{array}{l}\text { Upper } \\
\text { Bound }\end{array}$ & 354.40 & \\
\hline & $5 \%$ Trimmed Mean & 346.26 & \\
\hline & Median & 343.50 & \\
\hline & Variance & 781.319 & \\
\hline & Std. Deviation & 27.952 & \\
\hline & Minimum & 297 & \\
\hline & Maximum & 405 & \\
\hline & Range & 108 & \\
\hline & Interquartile Range & 44 & \\
\hline & Skewness & .408 & .319 \\
\hline & Kurtosis & -.822 & .628 \\
\hline
\end{tabular}

Dihasilkan Lower Bound dan Upper Bound 339.43 - 354.40. Berdasarkan temuan tersebut, dapat disimpulkan bahwa implementasi model pembelajaran problem solving berdasarkan Kejadian 26:1-35 di kalangan murid SOM Gereja Bethany se-kota Surabaya (Y) ada kategori "Sedang". Oleh karena itu, hipotesis pertama kecenderungan 
implementasi model pembelajaran problem solving berdasarkan Kejadian 26:1-35 di kalangan murid SOM Gereja Bethany se-kota Surabaya (Y) adalah "Sedang”.

Kecenderungan Mendengarkan (D1)

Dimensi Problem Solving Mendengarkan (X1)

Descriptives

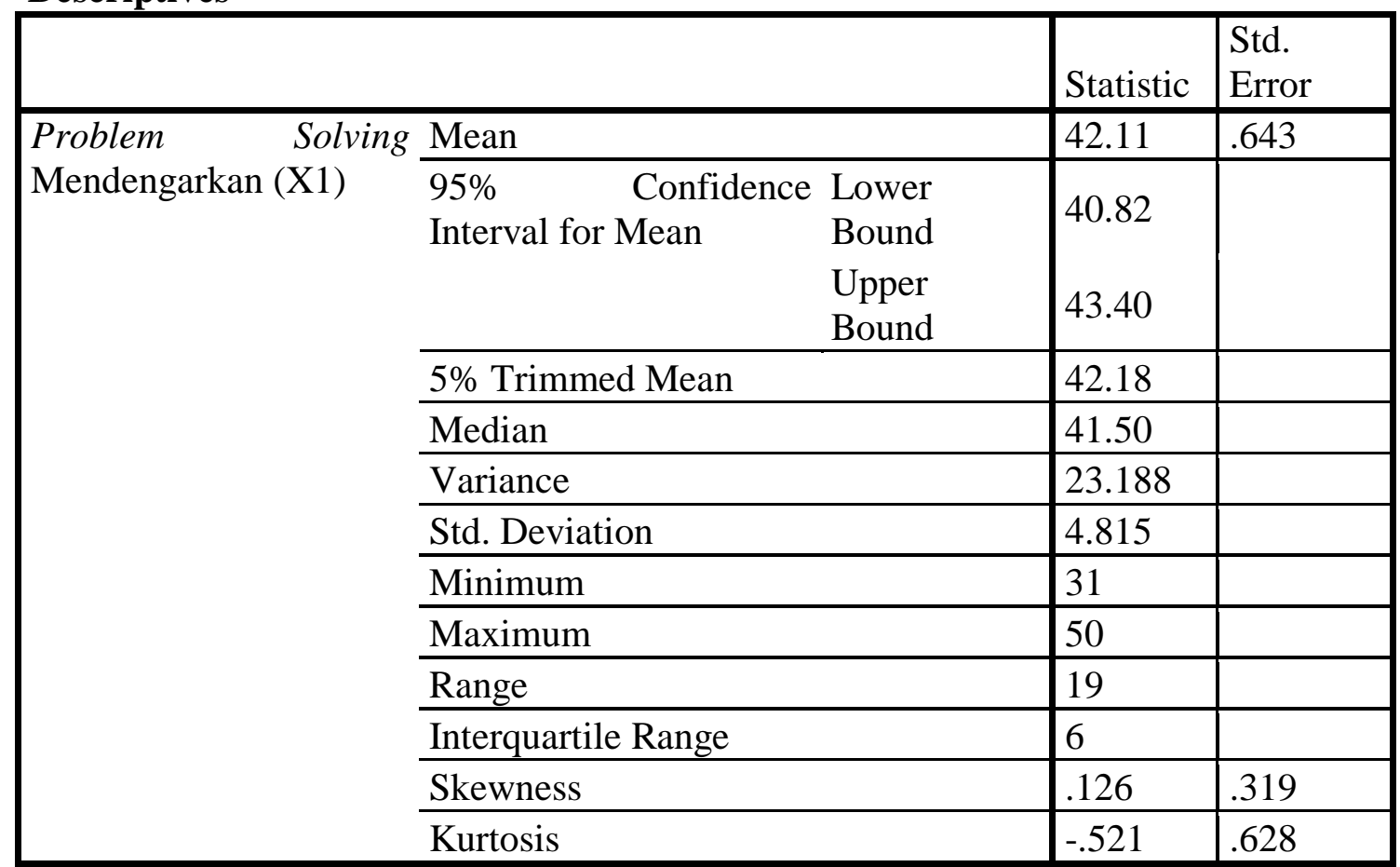

Dihasilkan Lower Bound dan Upper Bound 40.82-43.40. Berdasarkan temuan tersebut, dapat disimpulkan bahwa kecenderungan implementasi model pembelajaran problem solving berdasarkan Kejadian 26:1-35 dalam mendengarkan (D1), di kalangan murid SOM Gereja Bethany se-kota di kalangan murid SOM Gereja Bethany se-kota Surabaya (Y) ada kategori "Sedang". Hasil untuk exogenous variable (D1) sama dengan kesimpulan hipotesis pertama tentang kecenderungan endogenous variable.

Kecenderungan Berusaha (D2)

Dimensi Problem Solving Berusaha (X2)

\section{Descriptives}

\begin{tabular}{|c|c|c|c|}
\hline & & Statistic & $\begin{array}{l}\text { Std. } \\
\text { Error }\end{array}$ \\
\hline \multirow{6}{*}{$\begin{array}{ll}\text { Problem } & \text { Solving } \\
\text { Berusaha (X2) } & \end{array}$} & Mean & 43.39 & .477 \\
\hline & 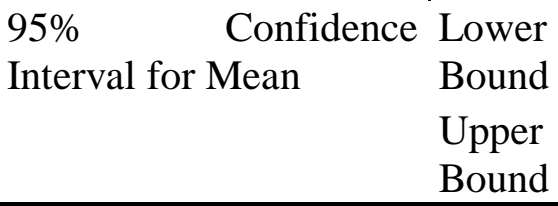 & $\begin{array}{l}42.44 \\
44.35\end{array}$ & \\
\hline & 5\% Trimmed Mean & 43.29 & \\
\hline & Median & 43.00 & \\
\hline & Variance & 12.752 & \\
\hline & Std. Deviation & 3.571 & \\
\hline
\end{tabular}




\begin{tabular}{|l|l|l|}
\hline Minimum & 38 & \\
\cline { 2 - 4 } Maximum & 50 & \\
\cline { 2 - 4 } Range & 12 & \\
\cline { 2 - 4 } Interquartile Range & 7 & \\
\hline Skewness & .480 & .319 \\
\hline Kurtosis & -1.047 & .628 \\
\hline
\end{tabular}

Dihasilkan Lower Bound dan Upper Bound 42.44-44.35. Berdasarkan temuan tersebut, dapat disimpulkan bahwa kecenderungan implementasi model pembelajaran problem solving berdasarkan Kejadian 26:1-35 dalam berusaha (D2), di kalangan murid SOM Gereja Bethany se-kota Surabaya (Y) ) ada kategori "Sedang". Hasil untuk exogenous variable (D2) sama dengan kesimpulan hipotesis pertama tentang kecenderungan endogenous variable.

Kecenderungan Media Pembelajaran (D3)

Dimensi Problem Solving Media pembelajaran (X3)

\section{Descriptives}

\begin{tabular}{|c|c|c|c|}
\hline & & Statistic & $\begin{array}{l}\text { Std. } \\
\text { Error }\end{array}$ \\
\hline \multirow{14}{*}{$\begin{array}{l}\text { Problem Solving Media } \\
\text { Pembelajaran (X3) }\end{array}$} & Mean & 41.04 & .625 \\
\hline & Confidence Lower & 3978 & \\
\hline & Interval for Mean & 59.10 & \\
\hline & $\begin{array}{l}\text { Upper } \\
\text { Bound }\end{array}$ & 42.29 & \\
\hline & 5\% Trimmed Mean & 41.13 & \\
\hline & Median & 41.00 & \\
\hline & Variance & 21.853 & \\
\hline & Std. Deviation & 4.675 & \\
\hline & Minimum & 30 & \\
\hline & Maximum & 50 & \\
\hline & Range & 20 & \\
\hline & Interquartile Range & 7 & \\
\hline & Skewness & -.245 & .319 \\
\hline & Kurtosis & -.423 & .628 \\
\hline
\end{tabular}

Dihasilkan Lower Bound dan Upper Bound 39.78-42.29. Berdasarkan temuan tersebut, dapat disimpulkan bahwa kecenderungan implementasi model pembelajaran problem solving berdasarkan Kejadian 26:1-35 dalam media pembelajaran (D3), di kalangan murid SOM Gereja Bethany se-kota Surabaya (Y) ) ada kategori "Sedang". Hasil untuk exogenous variable (D3) sama dengan kesimpulan hipotesis pertama tentang kecenderungan endogenous variable.

Kecenderungan Sumber Belajar Lain (D4)

Dimensi Problem Solving Sumber Belajar Lain (X4)

\section{Descriptives}




\begin{tabular}{|c|c|c|c|}
\hline & & Statistic & $\begin{array}{l}\text { Std. } \\
\text { Error }\end{array}$ \\
\hline \multirow{12}{*}{$\begin{array}{lr}\text { Problem } & \text { Solving } \\
\text { Sumber } & \text { Belajar yang } \\
\text { Lain }(X 4) & \end{array}$} & Mean & 127.00 & 1.507 \\
\hline & 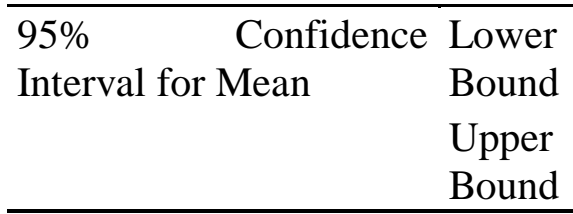 & $\begin{array}{l}123.98 \\
130.02\end{array}$ & \\
\hline & 5\% Trimmed Mean & 126.81 & \\
\hline & Median & 125.00 & \\
\hline & Variance & 127.200 & \\
\hline & Std. Deviation & 11.278 & \\
\hline & Minimum & 103 & \\
\hline & Maximum & 150 & \\
\hline & Range & 47 & \\
\hline & Interquartile Range & 16 & \\
\hline & Skewness & .453 & .319 \\
\hline & Kurtosis & -.516 & .628 \\
\hline
\end{tabular}

Dihasilkan Lower Bound dan Upper Bound 123.98-130.02. Berdasarkan temuan tersebut, dapat disimpulkan bahwa kecenderungan implementasi model pembelajaran problem solving berdasarkan Kejadian 26:1-35 dalam sumber belajar lain (D4), di kalangan murid SOM Gereja Bethany se-kota Surabaya (Y) ) ada kategori "Sedang". Hasil untuk exogenous variable (D4) sama dengan kesimpulan hipotesis pertama tentang kecenderungan endogenous variable.

Kecenderungan Refleksi (D5)

Dimensi Problem Solving Refleksi (X5)

Descriptives

\begin{tabular}{|l|l|l|l|}
\hline & Statistic & $\begin{array}{l}\text { Std. } \\
\text { Error }\end{array}$ \\
\hline $\begin{array}{l}\text { Problem } \\
\text { Refleksi (X5) }\end{array}$ & Solving & 93.38 & 1.125 \\
\hline & $\begin{array}{l}\text { Mean } \\
\text { Interval for Mean } \quad \begin{array}{l}\text { Bound } \\
\text { Upper } \\
\text { Bound }\end{array}\end{array}$ & 91.12 & \\
& 94.63 & \\
\hline $\begin{array}{l}\text { 5\% Trimmed Mean } \\
\text { Median }\end{array}$ & 93.65 & \\
\hline Variance & 93.00 & \\
\hline Std. Deviation & 70.857 & \\
\hline Minimum & 8.418 & \\
\hline Maximum & 74 & \\
\hline Range & 105 & \\
\hline Interquartile Range & 16 & \\
\hline Skewness & -.222 & .319 \\
\hline
\end{tabular}


Dihasilkan Lower Bound dan Upper Bound 91.12-94.83. Berdasarkan temuan tersebut, dapat disimpulkan bahwa kecenderungan implementasi model pembelajaran problem solving berdasarkan Kejadian 26:1-35 dalam refleksi (D5), di kalangan murid SOM Gereja Bethany se-kota Surabaya (Y) ada kategori "Sedang". Hasil untuk exogenous variable (D5) sama dengan kesimpulan hipotesis pertama tentang kecenderungan endogenous variable.

\section{Uji Hipotesa Kedua}

Hipotesis kedua adalah dimensi yang paling dominan implementasi model pembelajaran problem solving berdasarkan Kejadian 26:1-35 di kalangan murid SOM Gereja Bethany se-kota Surabaya adalah dimensi "Sumber belajar yang lain".

Uji hipotesis kedua dilakukan dengan hasil analisis hubungan sampel antara dimensi (Y) yaitu $\mathrm{R}$ Square. Dengan menghitung uji regresi signifikan. Dari perhitungan kontribusi masing-masing dimensi exogeneous terhadap endogeneous variable dapat diringkas dalam tabel berikut:

Tabel 3. Rekapitulasi Asosiasi

\begin{tabular}{|l|l|l|l|l|}
\hline No & Dimensi & R & R square & Kontribusi \\
\hline 1 & Mendengar & 0,809 & 0,655 & $65 \%$ \\
\hline 2 & Berusaha & 0,856 & 0,732 & $73 \%$ \\
\hline 3 & Media Pembelajaran & 0,797 & 0,635 & $63 \%$ \\
\hline 4 & Sumber Belajar Lain & 0,909 & 0,826 & $83 \%$ \\
\hline 5 & Refleksi & 0,835 & 0,697 & $70 \%$ \\
\hline
\end{tabular}

Dari tabel rangkuman hubungan dan kontribusi variabel exogenous variable terhadap endogenous variable diketahui bahwa hubungan antara dimensi sumber belajar lainnya (D4) memiliki nilai determinasi tertinggi yaitu 0,826 dengan kontribusi variabel endogenous sebesar $83 \%$. Hal ini menunjukkan bahwa dimensi yang paling dominan menentukan implementasi model pembelajaran problem solving berdasarkan Kejadian 26:1-35 di kalangan murid SOM Gereja Bethany se-kota Surabaya (Y) adalah sumber belajar lain (D4).

Oleh karena itu, dari pengujian dapat disimpulkan bahwa hipotesis dimensi sumber belajar lain (D4) diterima karena dimensi dominan terbesar dalam implementasi model pembelajaran problem solving berdasarkan Kejadian 26:1-35 di kalangan murid SOM Gereja Bethany se-kota Surabaya adalah sumber belajar lain (D4).

\section{Uji Hipotesa Ketiga}

Hipotesis ketiga adalah bahwa kategori latar belakang yang lebih dominan dalam menentukan implementasi model pembelajaran problem solving berdasarkan Kejadian 26:1-35 di kalangan murid SOM Gereja Bethany se-kota Surabaya adalah "pendidikan".

Untuk mengetahui apakah hipotesis ketiga diterima digunakan Classification and regression Trees (CART) pada taraf signifikansi 0,05 .

Untuk mengetahui kategori latar belakang mana yang paling berpengaruh terhadap variabel Y, akan dilakukan uji one-way anova pada taraf signifikansi 0,05. hasil analisis antara exigenous variable dan endogenous variable menunjukkan bahwa 
latar belakang Pendidikan merupakan kategori latar belakang yang paling dominan menentukan implementasi model pembelajaran problem solving berdasarkan Kejadian 26:1-35 di kalangan murid SOM Gereja Bethany se-kota Surabaya (Y). Latar belakang pendidikan menunjukan koefesien kontigensi sebesar 0,899.

Dengan demikian, dari uji hipotesis yang dilakukan dapat disimpulkan bahwa hipotesis ketiga diajukan dengan kategori latar belakang yang paling dominan penentuan implementasi model pembelajaran problem solving berdasarkan Kejadian 26:1-35 di kalangan murid SOM Gereja Bethany se-kota Surabaya (Y) adalah pendidikan dinyatakan diterima.

\section{KESIMPULAN}

Berdasarkan hasil penelitian lima dimensi yang termaktud dalam Kejadian 26:135 diperoleh bahwa dimensi yang paling mempengaruhi implementasi model pembelajaran problem solving di kalangan murid SOM Bethany se-kota Surabaya adalah "sumber belajar lain" dan kategori yang paling mempengaruhi implementasi model pembelajaran problem solving berdasarkan kejadian 26:1-35 di kalangan murid SOM Gereja Bethany se-kota Surabaya adalah kategori latar belakang "Pendidikan". Peneliti memberikan kontribusi berupa saran dan masukan sebagai berikut:

Pertama, agar semua murid SOM Gereja Bethany se-kota dapat melakukan model pembelajaran problem solving berdasarkan Kejadian 26:1-35 berdasarkan uraian pembahasan, dengan menggunakan indikator sebagai langkah-langkah penerapan pelajaran SOM dengan model pembeajaran problem solving.

Kedua, guru SOM melakukan penilaian terhadap metode pengajaran, sehingga dapat berpartisipasi aktif dalam proses pembelajaran siswa maupun guru. Dan juga pengajar SOM mengikuti seminar, workshop pendidikan sebagai kesempatan untuk mengembangkan skill dalam mengajar.

Ketiga, Sekolah Orientasi Melayani mengadakan workshop model pembelajaran problem solving Berdasarkan Kejadian 26:1-35.

\section{DAFTAR PUSTAKA}

A Anditha Sari. Komunikasi Antar Pribadi. 1st ed. Yogyakarta: Deepublish, 2017.

Abraham Alex Tanuseputra. Kesembuhan Ilahi Dan Berkat. 1st ed. Surabaya: House of Blessing, 2009.

Arikunto, Suharsimi. Metodologi Penelitian. Yogyakarta: Binarupa Aksara, 2008.

_. Prosedur Penelitian: Suatu Pendekatan Praktek. Jakarta: Rineka Cipta, 2010.

Cecil Sherman. Cecil Sherman Formations Commentary Vol. I. 1st ed. Macon: Smyth \& Helwys Publishing, 2006.

George W Coats. Genesis: With An Introduction To Narrative Literature. 1st ed. Grand Rapids, Michigan: William B, Eerdmans Publishing Company, 1983.

- Genesis With An Introduction To Narrative Literature. 1st ed. Grand Rapids, Michigan: William B, Eerdmans Publishing Company, 1983.

H.N Ridderbos. Studies in Scripture and Its Authority. 1st ed. St. Catharines: Paideia Press, 1978.

Hariono Sumarsono. Hidup Berkelimpahan. 1st ed. Bandung: Kalam Hidup, 2004.

Jack Hayford. Examining Excellence in The Creator's Ways: A Study in The Book of 
Genesis. 1st ed. Nashville: Thomas Nelson, 1997.

John Maxwell. Mengembangkan Kepemimpinan Di Dalam Diri Anda. 1st ed. Jakarta: Binarupa Aksara, 1995.

Jonathan A Trisna. Mengatasi Masalah Hidup. 1st ed. Bandung: Kalam Hidup, 1998. Mengatasi Masalah Hidup. 1st ed. Bandung: Kalam Hidup, 1998.

Kenneth E Hagin. Rahasia Hidup Berkelimpahan. 1st ed. Jakarta: Metanoia, 1996.

Lee, Fred N Kerlinger and Howard B. Foundation of Behavioral Research. Forth Worth: Harcount College Publisher, 2000.

Mark Water. The Book of Genesis Made Easy. 1st ed. Hampshire: John Hunt Publishers Ltd, 2000.

Mc Gee. Thru The Bible Commentary: The Law (Genesis 16-33). 1st ed. Nashville: Thomas Nelson, 1991.

Pangesti Wiedarti. Menuju Budaya Menulis: Suatu Bunga Rampai. 1st ed. Yogyakarta: Tiara Wacana, 2005.

Robert Smith. Studies in Genesis. 1st ed. Oak Harbor: Derdick Publishing, 1997.

Roy Gingrich. The Book of Genesis. 1st ed. Memphis: Riverside Printing, 1998.

-. The Book of Genesis. 1st ed. Memphis: Riverside Printing, 1998.

Rusman. Model-Model Pembelajaran. 5th ed. Jakarta: PT. Rajagrafindo Persada, 2012. . Model-Model Pembelajaran. 5th ed. Jakarta: PT. Rajagrafindo Persada, 2012.

Sasmoko, Frederikus Fios and. Neuro Research Method: A Synthesis Between Hermeneutics and Positivism. Advanced S. American Scientific Publishers, 2016.

Slameto. Belajar Faktor-Faktor Yang Mempengaruhinya. 1st ed. Jakarta: Rineka Cipta, 2013.

Stuart Briscoe. The Preacher's Commentary Series: Volume I. 1st ed. Nashville, Tennessee: Thomas Nelson, 1987.

- The Preacher's Commentary Series Volume I. 1st ed. Nashville, Tennessee: Thomas Nelson, 1987.

Suwana. Pengajaran Mikro. 1st ed. Yogyakarta: Tiara Wacana, 2005.

Walter Brueggemann. Genesis: A Bible Commentary for Teaching and Preaching. 1st ed. Atlanta: John Knox Press, 1982.

- Genesis: A Bible Commentary for Teaching and Preaching. 1st ed. Atlanta: John Knox Press, 1982.

Wina Sanjaya. Strategi Pembelajaran Berorientasi Standar Proses Pendidikan. 1st ed. Jakarta: Kencana, 2008.

Winastwan Gora dan Sunarto. Pakematik: Strategi Pembelajaran Inovatif Berbasis TIK. 1st ed. Jakarta: Elex Media Komputindo, 2010. 